\title{
UN ESTALLIDO DE INTOXICACION POR ALIMENTOS
}

\author{
Dr, MARIO MIRANDA y Srs. IGNACIO PINO y RENE GOMEZ \\ Servicio Nacional de Salud, Zona VII Sur-Oriente. Santiago.
}

Durante el fin de la primera semana de Febrero de 1955 ocurrió en Santiago un brote de intoxicación por alimentos que afectó a más de un centenar de niños del establecimiento denominado "Ciudad del Niño", ubicado en la Comuna San Miguel en la Zona Sur de la ciudad. Nos ha parecido de interés hacer la presentación del estudio efectuado en dicha ocasión, porque no sabemos que exista en la casuística nacional otro ejemplo de intoxicación por alimentos en el que haya enfermado un número tan considerable de personas.

\section{ANTECEDENTES}

Las primeras noticias llegadas a conocimiento de las autoridades sanitarias ef Domingo 6 en la mañana. hicieron que se arbitraran de inmediato las medidas necesarias para el tratamiento y atención de los menores todavia enfermos, a la vez que se dicra comienzo a la investigación epidemiológica corresponmiente, la que propotciono la información que pasamos a detallar:

El Sábado 5. a las 19 hotas, comenzaron a requeric los servicios de la enfermeria de la Ciudad del Niño. varios menores que presentahan un violento cuadro consistente en dolores abdominales intensos, vómitos repetidos y diarteas profusas. Se solicitó entonces por teléfono la ayuda de la Posta de Urgencia del Hospital Bartos Laco, pero como el aúmero de en- fermos continuabj aumentando a medida que el tiempo transcurría. La Posta de Uraencia mencionada pidió a su vez la cooperación de la Posta Central y de los Hospitalcs "Manuel Arriaran". "Luis Calvo Mackenna" y "Roberto del Rio", donde fucron atendidos y hospitalizados por algunas horas 111 giños.

Todos los afectados presentaton el mismo cuadro ya descrila, con difcrentes grados de intensidad, $\sin$ que en ningún caso fuera de excepcional gravedad. Tal es asi que la casi totalidad de los menores hospitalizados fueton devueltos a la Ciudad del Niño en ef curso del dia siguiente, con la sola excepción de dos de cllos a quícnes $5 e$ tuvo en observación por 48 horas $\mathrm{y}$ que posteriormente se reintegraron al establecirniento en buenis condiciones.

Investigación en it terreno.

Dispues de una encaesta preliminar en la Enfermería de la Ciudad del Niño, se reatizó la visita a las tocinas. donde la investigación para deteminar el origen del arcidente se centralizó desde un comienzo en la úlcima comida laetha por los afectodos. ya que el corto período dentro del cual la casi totalidad de los niños initió su siniomatología, apuntaba fuertemente diacia la cena habida a las 18 horas del Sábado 5.

Ein las cocinas se pudo constatac los sigruimtes bechos:

1. No quedaban restos de los alimentos preparados que se consumieron el día anteriot. Mas aún. los continentes respectivos habian sido lavados y se estaba preparando en ellos el almuerzo de ese dia. 
2. El Sabudo 5 los riños habian consumido los alimentos que se detallan a continuación:

Desayuno ( 8 horas): Café con leche caliente (a partir de leche fresca). Azúcar y pan:

Almuerzo ( 12 horas): Cazuela de riñones. Simola con papas, pan:

Comida (18 horas): Guiso de riñones caliente. Leche tibia (a partir de leche en polso) con azúcar. Pan. Tomates frescos.

3. En la revisión de los utensilios usados en la preparación de los aljmentos no se encontró nada anozmal que hiciera pensar en una intoxicación de tipo químico. En efecto, ni las matmitas de acero inoxidable, ni los cucharones u otros artefactos examiaados. merccieron objeción desde este punto de vista. Hace excepción a lo anterior una paleta de madera que se usaba paea reconstituic leche desecada y a la que posteriormente nos referitemos con mas detalles porque nos pareció de interćs desde el punto de vista bacteriológico.

4. El personal que trabajó e! dia del accidente era d ustal. Fintre cllos no babiz enfermos ni se constató lesiones supuradas al examinarlos.

5. Se comprobó la cxistencia en las cocinos de abundantes moscas, precatia limpieza de paredes y mesones: proximidad de carros de basura expuestos al sol y destapados y finalmente puertas y ventanas ampliamente abiertas.

6. La conservación de alimentos en el refrigerador se hacía en buenas condiciones a una temperatura de 4 grados. Allí estaban almacenados los rinones de cordero usados el día anterior en el almuerzo y la cena: provenian del Sur. habian sido suminjstrados en estado de congelación y se estaban consumiendo desde bacia varios dias en ese establecimiento $y$ en ottos dependientes del Consejo de Defensa del Niño.

7. Los demás ingredientes usados en la confesción de los alimentos como harina, fideos, aceite, leche en polvo, etc. se guardaban en una despensa. contigua a la cocina y malamente defendida contra ratones: en efecto, se encontraron numerosas prucbas de fresencia de rocdores.

8) Las comates que se consumicron cridos eran cosechados en la propia buetta del establecimiento, estaban en buen grado de madurez $y$ fueron lavados en agua corriente antes de ser servidos enteros. (Los niños acostumbraban comerlos a guisa de postre).

9. E] agna utilizada tanto en la preparación de los alinentos como para bebida provenía de un pozo del propio estableciniento. obtcnida a gran profundidad y elorada.

El interrogatorio al personal de la cocina tcveló que el dia anterior se prepararon junto con el almuerzo, a las II de la mañana aproximadamente, 150 litros de leche. a partir de la lecile desecada, la que se mezcló en una matmita de atero inoxidable con la cantidad requerida de agua tibia, y azucar, revolviendo el total con la paleca de madera ya mencionada, que a la vez scrvia para mezelar ottos alimentos como arroz cocido. sémola. etc. Dicha paleta se encontró cn el nomento de la investigación apoyada en al suelo y con restos de arroz cocido adharidos en su superficie. Presentaba en los bordes, toscamente labrados, numerosas irregularidades en las que se había coleccionado abundante cancidad de rnarerias excrañas. La leche así reconstituida fuć dejada en la marmita (que se tapó inmediatamente que se efectuó la opetación hasta las 18 horas. en que, sin previo calentamiento se repartió a los niños en cantidad de $200 \mathrm{cc}$. aproximadarmente a cada uno. El nncargado de la mezcla refirió que. do ordinario esta reconstitución de la leche sc efectuaba antes de la cena, pero desde hacia aproximadamento 15 dias habia optado por el procedimiento que bemos detallado, que Is evitaba trabajo a ultima hora. Esta modificación no había llamado mayormente la atención del resto del personal de las corinas.

Se procidió a tomar mucstras para examen químico-toxicológico de todos los ingredientes y matcrias primas usadas en la cocina y para examen bacterioló. gico. de varios frotes de la paleta en eucstión, del agua de consumo y del vómito de uno de los enfermos, obtecido en el momento de la visita a la Enfermeria.

\section{ANÁLISIS ESTADÍSTICO DE LOS DATOS RECOGIDOS}

La encuesta epidemiológica hecha mediante un cuestionario especial ideado para el objeto, se realizó en los 331 niños que cenaron Ia noche anterior, obteniéndose una serie de datos que fueron tabulados y analizados estadísticamente y que vamos a detallar en seguida:

En el cuadro No 1 se observa el modelo de la encuesta utilizada; en él se colocaron los datos que nos parecieron fun-

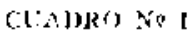

MODELO DE LA ENCUESTA UTILIZADA EN LA INVESTIGACION EPIDEMLOLOGICA

\begin{tabular}{|c|c|c|c|c|c|c|c|c|c|c|c|c|}
\hline $\begin{array}{l}\text { Nombre } \boldsymbol{y} \\
\text { Apeltido }\end{array}$ & Edad & \multicolumn{2}{|c|}{$\begin{array}{l}\text { Cen6 (sí o } \\
\text { Riñones, Leche, }\end{array}$} & $\begin{array}{l}\text { no) } \\
\text { Tocoates }\end{array}$ & \multicolumn{2}{|c|}{$\begin{array}{c}\text { Enfermó } \\
(\text { sí o no) }\end{array}$} & $\begin{array}{r}\text { Hota los } \\
\text { sintomas }\end{array}$ & $\begin{array}{r}\text { S i } \\
\text { Dc.or abd. }\end{array}$ & $\begin{array}{c}t \circ \mathrm{m} \\
\text { Vónito }\end{array}$ & $\begin{array}{l}\text { a } 8 \\
\text { Diartea }\end{array}$ & \multicolumn{2}{|c|}{$\begin{array}{l}\text { Recurriö a } \\
\text { enfermeria } \\
\text { (sí o no) }\end{array}$} \\
\hline$\ldots$ & . & $\cdots$ & $\ldots$ & $\cdots$ & . & + & . & $\ldots$ & $\ldots$ & . & $\cdots$ & $\cdots$ \\
\hline$\cdots$ & $+\cdots$ & $\cdots$ & , & . & $\cdots$ & $\cdots$ & $\cdots$ & $\ldots$ & $\cdots$ & $\cdots$ & $\cdots$ & $\cdots$ \\
\hline$\ldots$ & $\ldots$ & $\cdots$ & $\cdots$ & $\cdots$ & $\ldots$ & . & $\ldots$ & $\ldots$ & . & $\ldots$ & $\cdots$ & $\ldots$ \\
\hline$\cdots$ & $\cdots$ & $\cdots$ & $\cdots$ & $\cdots$ & $\ldots$ & - & + & $\ldots$ & $\cdots$ & + & $\because$ & \\
\hline$\cdots$ & $\ldots$ & , & $\ldots$ & $\ldots$ & $\ldots$ & $\ldots$ & $\ldots$ & $\ldots$ & $\cdots$ & $\cdots$ & $\ldots$ & $\cdots$ \\
\hline$\cdots$ & $\ldots$ & . & $\ldots$ & $\cdots$ & $\cdots$ & . & . & . & $\ldots$ & $\cdots$ & $\ldots$ & . \\
\hline
\end{tabular}


CUADRO X: 2

DISTRIBUCION DE PERSONAS QUE CENARON, POR EDAD, SEXO. PRESENCIA O NO DE ENFERMEDAD

\begin{tabular}{|c|c|c|c|c|}
\hline Edad y Sexo & Sanos & Entermos & Total & $\%$ erfermos \\
\hline $\begin{array}{l}5-9 \text { años } \\
\text { Honibres } \\
\text { Mujeres }\end{array}$ & $\begin{array}{r}14 \\
7 \\
7\end{array}$ & $\begin{array}{l}615 \\
4.3 \\
23\end{array}$ & $\begin{array}{l}80 \\
50 \\
30\end{array}$ & $\begin{array}{l}82,5 \\
86,1 \\
56,7\end{array}$ \\
\hline $\begin{array}{l}10-14 \text { afios } \\
\text { Honbres } \\
\text { Mujeres }\end{array}$ & $\begin{array}{l}60 \\
3,3 \\
27\end{array}$ & $\begin{array}{r}144 \\
93 \\
46\end{array}$ & $\begin{array}{r}2014 \\
1.51 \\
7.1\end{array}$ & $\begin{array}{l}70,6 \\
74,8 \\
63,0\end{array}$ \\
\hline $\begin{array}{l}15.19 \text { atios } \\
\text { Hombires } \\
\text { 31ujeres }\end{array}$ & $\begin{array}{l}311 \\
1.3 \\
17\end{array}$ & $\begin{array}{r}17 \\
14 \\
3\end{array}$ & $\begin{array}{l}47 \\
27 \\
311\end{array}$ & $\begin{array}{l}36,2 \\
51,9 \\
15,0\end{array}$ \\
\hline $\begin{array}{l}\text { TOTAL } \\
\text { Hombres } \\
\text { Mujeres }\end{array}$ & $\begin{array}{r}104 \\
1.3 .3 \\
31\end{array}$ & $\begin{array}{r}227 \\
155 \\
72\end{array}$ & $\begin{array}{l}3.31 \\
2,18 \\
123\end{array}$ & $\begin{array}{l}50 \\
74,5 \\
53,5\end{array}$ \\
\hline
\end{tabular}

damentales y cuya averiguación resultaba más fácil, dejando de mano aquellos otros como el síntoma náuseas de difícil investigación en niños de poca edad.

El cuadro $N^{\circ} 2$ divide el total de niños que cenaron según edad, sexo y presencia o no de enfermedad. Se observa que la tasa de ataque fué más alta en los hombres que en las mujeres, en todos los grupos expuestos y que la susceptibilidad fué mayor en los niños de menor edad. Estas diferencias entre hombres y mujeres son estadísticamente significativas.

EI cuadro N? 3 demuestra la distribución de los enfermos según el tiempo que transcurrió entre la comida y la presentación de los sintomas; se observa que el grupo más grande de enfermos se presentó entre tres y cinco horas. El tiempo medio de aparición de los síntomas, considerando el total de los enfermos fué de 3,6 horas y el $86 \%$ de los casos ocurrieron antes de las 5 horas.

El cuadro $N^{\circ} 4$ nos indica que el síntoma presente en casi el total de los enfermos fué el dolor abdominal, de intensidades variables y que lo siguieron en orden de frecuencia los vómitos y la diarrea.

Del cuadro No 5 se deduce que la sintomatología fué intensa en el $85 \%$ de los casos, a tal punto que requirieron atención médica, ya sea en el propio establecimiento o en otros hospitales.

CLADRO Na 3

DISTRIBUCION DE LOS ENFERMOS SEGUN TIEMPO TRANSCURRIDO ENTRE $L A$ COMIDA $Y$ LA APARICION DE LOS SINTOMAS

\begin{tabular}{cc}
\hline Intervalo en horas & Número de eulermos \\
\hline Menos de l & 1 \\
$1-2$ & 74 \\
3.4 & 122 \\
5.6 & 30 \\
7 y mas & - \\
\hline TOTAL & 227 \\
\hline
\end{tabular}

CUADRO NQ4

DISTRIBUCION DE LOS ENFERMOS SEGUN FRECUENCIA DE LOS SINTOMAS

\begin{tabular}{lccc}
\hline & Diactea & Vómitos & $\begin{array}{c}\text { Dolores } \\
\text { abdominales }\end{array}$ \\
\hline Número de enfermos & 190 & 214 & 225 \\
\% del total clue enírmaton & 83 & 94 & 99 \\
\hline
\end{tabular}

El cuadro No 6 trata de relacionar la presencia de enfermedad con el tipo de alimento ingerido a la vez que determinar si en el grupo de los que no consumieron cada uno de estos alimentos hubo también enfermos. La mayoría de los afectados había consumido más de uno de los tres tipos considerados; si se observan aisladamente se ve que los tres dan tasas de ataque aproximadamente iguales. $\mathrm{Sin}$ embargo, podemos descartar los tomates, que además de figurar con una tasa de ataque más baja, no podrian haber ocasionado el cuadro, a no ser que se tratara de una intoxicación de tipo químico, pero ya con caracteres diferentes.

El problema queda entonces reducido a determinar si el causante del accidente fué el guiso de riñones o la leche ingerida por los niños. De este cuadro se deducen dos hechos de importancia; desde luego el que el guiso de riñones no pudo haber sido el causante, ya que en tres casos de nin̄os que no lo consumieron se presentaron los síntomas de la intoxicación (precisamente estos niños habían consumido leche). El otro hecho, de tipo negativo, es que en ninguno de los 30 niños que se abstuvieron de consumir leche. se presentó el cuadro en cuestión. Esta cifra que llama la atención es estadísticamente significativa y por tanto puede afirmarse que los que no tomaron leche tuvieron menos riesgo de enfermar.

Debido a que la mayoría de los enfermos ingirió más de un alimento y a fin de determinar el efecto específico de uno solo de ellos en el cuadro $\mathrm{N}^{o} \mathbf{7}$ se tcmaron tasas de ataque para combinaciones de estos alimentos. Aquí también llama la atención el hecho de que, a pesar de que las tasas de ataque para los que consumieron leche no son más altas que las correspondientes al grupo que comió el guiso

CL̈ADRO Na 5

DISTRIBUCION DE LOS ENFERMOS SEGUN INTENSIDAD DE LOS SINTOMAS

\begin{tabular}{lcc}
\hline & $\begin{array}{c}\text { Recurrieron a } \\
\text { Enfemería }\end{array}$ & $\begin{array}{c}\text { No recurrieron } \\
\text { a Enfermeria }\end{array}$ \\
\hline $\begin{array}{l}\text { Numero de enfermog } \\
\% \text { de eviermos del total de niños }\end{array}$ & 198 & 29 \\
\hline
\end{tabular}


CUATJKO N०

TASA DE ATAQUE PARA ALIMENTOS QUE SE ESPECITICAN SEGUN RESULTADO DE LA ENCUESTA

\begin{tabular}{|c|c|c|c|c|c|c|}
\hline \multirow[t]{2}{*}{ Aliment } & \multicolumn{3}{|c|}{ Comieron } & \multicolumn{3}{|c|}{ No comlecon } \\
\hline & Total & Enfermaron & $\%$ & TotaI & Eufermaron & $\%$ \\
\hline $\begin{array}{l}\text { Ritisn to } \\
\text { riñules } \\
\text { Jueche } \\
\text { Tomates }\end{array}$ & $\begin{array}{l}294 \\
301 \\
331\end{array}$ & $\begin{array}{l}224 \\
227 \\
227\end{array}$ & $\begin{array}{l}73,2 \\
75,4 \\
68,5\end{array}$ & $\begin{array}{r}37 \\
30 \\
0\end{array}$ & $\begin{array}{l}3 \\
? \\
\vdots\end{array}$ & $\begin{array}{l}8 \\
0 \\
0 \\
0\end{array}$ \\
\hline
\end{tabular}

de riñones por el hecho de estar estos alimentos asociados, en el grupo de los que comieron este guiso solo, no hubo ningún caso de enfermedad, lo que atestigua que estos niños tuvieron menos riesgo de enfermar.

En resumen: Todos los enfermos tienen entre sus antecedentes el haber ingerido leche; ninguno de los que se abstuvo de este alimento enfermó. Casi todos los enfermos tienen también entre sus antecedentes el haber comido guiso de riñones, excepto tres de ellos. Finalmente, del grupo de niños que no consumió este alimento, ninguno manifestó enfermedad.

El Laboratorio informó posteriormente que el examen químico-toxicológico de los ingredientes utilizados en la cocina no reveló la presencia de substancias tóxicas. El resultado de los exámenes bacteriológicos del raspado de la paleta empleada indicó una contaminación marcada con "todo tipo de gérmenes saprófitos y comensales con predominio de E. Coli". En la muestra de vómitos se encontró una que otra colonia de Estafilococo Patógeno.

El agua de consumo reveló abundante B. Coli con presencia de Escherichia Coli.

\section{DISCUSIóN Y CONCLUSIONES}

Del análisis estadístico se desprende que la leche manipulada en las condiciones descritas e ingerida sin calentamiento fué la causante de la intoxicación que nos ocupa. Respecto al agente causal, las características del periodo de incubación y la sintomatología de los enfermos indican intoxicación por enterotoxina estafilocócica. En este caso estaban presentes las tres condiciones necesarias para la producción de esta toxina, a saber: medio apropiado para el desarrollo de este tipo de gérmenes, tiempo y temperatura suficientes y numerosas posibilidades de contaminación. La contaminación ocasional masiva debió ocurrir en el momento de la preparación en forma que no podemos asegurar, pero que no es difícil imaginarse dadas las condiciones de saneamiento deficiente del local y de los utensilios em-
CINI)120 Y: 7

TASAS DE ATAQUE PARA COMBINACION DE LOS DOS $\Lambda$ LIMENTOS SOSPECHOSOS

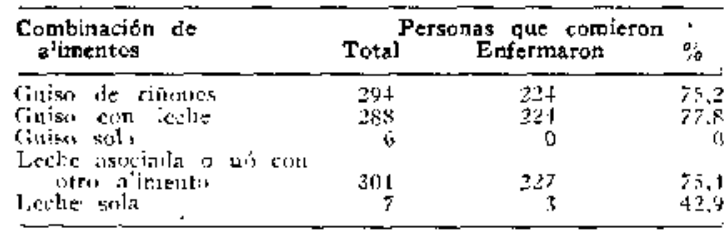

pleados. E1 tiempo transctirrido desde la preparación del alimento hasta su consumo, que fué de 7 horas, es más que suficiente para la producción abundante de toxina a partir de una cepa apropiada, que incluso puede haber hallado poca competencia microbiana por tratarse de leche reconstituída $\mathrm{y}$, finalmente, la temperatura no pudo haber sido más favorable ya que se partió de leche tibia conservada en una marmita tapada y en un ambiente caluroso (ese Sábado la temperatura máxima fué de 29 grados a las 16 horas).

Finalmente el hecho de que ta totalidad de los enfermos se recobraran en forma rápida es también indicativo del tipo de intoxicación que se ha mencionado.

\section{RESUMEN}

Se describe un brote de intoxicación alimenticia que afectó a $\mathbf{2 2 7}$ niños internados en la "Ciudad del Niño" de Santiago. Realizada la encuesta epidemiológica correspondiente, se llega a la conclusión de que su causa fué la ingestión de leche que contenía estafilococos patógenos, cuya enterotoxina fué la que ocasionó las manifestaciones clínicas observadas en estos casos.

\section{SUMMARY}

\section{AN OUTBREAK OF FOOD POISONING.}

An outbreak of food poisoning, affecting 227 children interned in the "City of the Child" of Santiago, is described. An epidemiological investigation done, leads into the conclusion that it was produced by the ingestion of milk containing staphylococeus, which enterotoxin was the cause that produced the clinical symptoms observed in these cases.

\section{BIBLIOGRAFİA}

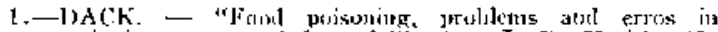

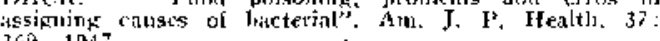
I6i, 1947 .

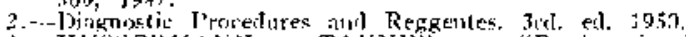

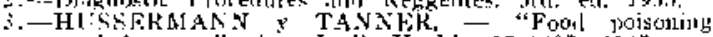

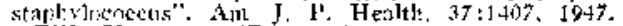

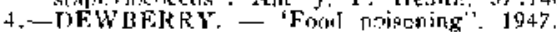

5.-KARFF. TABACK y HEARD. - "A coordinated Inrestigation of a food poisoning outbreak". P. Health Reprits. 67:909, 1952.
} 